\title{
A LITERATURA NA REDE: UMA LITERATURA ENREDADA?
}

\section{LITERATURE ON THE INTERNET: AN ENTANGLED LITERATURE?}

SÉRgio LuIz PRAdo BELLEI*

RESUMO: Liberado do peso de sua materialidade pela tecnologia digital, o texto literário hipertextualizado e disponibilizado em rede torna-se, em vários aspectos, mais poderoso e eficaz: pode agora ser acompanhado de uma enorme quantidade de explicações contextuais impossíveis de serem abrigadas nos limites do livro impresso e torna-se acessível a um público leitor mais global do que local. Disseminado em rede, por outro lado, o texto pode sofrer um apagamento das condições materiais de produção que constituem parte integrante de seu sentido. Essas duas perspectivas podem ser exemplarmente percebidas na obra do poeta inglês William Blake, autor multimídia avant la lettre.

PALAVRAS-CHAVE: Texto literário. Hipertexto digital. Novas tecnologias.

ABSTRACT: Released from the materiality burden by digital technologies, the hypertextualized literary text which is made available on the internet becomes more empowered

\footnotetext{
* Docente da UFMG - Universidade Federal de Minas Gerais. E-mail: sergiobellei50@gmail.com
} 
and efficient in several ways: it can now be linked to a vast quantity of contextual explanations that were impossible to be included due to the limitations of the printed book, and it also becomes accessible to a more global public reader than a local one. On the other hand, once it is disseminated on the internet, the literary text can undergo an obliteration of the material conditions of production that constitute a crucial part of its meaning. These two perspectives can be perfectly understood in the work of the English Poet William Blake, a multimedia author avant la lettre.

KEYWORDS: Literary text. Digital hypertext. New technologies.

\section{A questão da tecnologia: duas perspectivas}

A migração em massa de textos literários para a rede eletrônica nas últimas três ou quatro décadas pode ser compreendida de formas diversas, dependendo do entendimento que se tenha sobre o conceito de tecnologia. A tecnologia é frequentemente percebida em termos de seu valor instrumental, ou seja, como uma caixa de ferramentas que amplia o potencial de tecnologias anteriores. No mito platônico da invenção da escrita, é esta a perspectiva adotada pelo deus Theuth no momento em que apresenta ao rei do Egito a sua mais recente invenção, aquela que transformaria os egípcios em seres mais eficientes e poderosos por meio da aquisição da capacidade de escrever. Theuth explica: "Esta descoberta, ó rei, tornará os egípcios mais instruídos, pois representa o remédio (phármacon) tanto para a memória (mneme) quanto para o saber (sophia)" (PLATO, 1925, p. 274).

Os fonemas codificados em letras tornar-se-iam mais 
produtivos, porque seriam transformados em uma prótese da memória e do conhecimento vivos e interiorizados. Operacionalizados pela tecnologia, constituiriam um sistema abstrato de sinais, um aparato capaz de compensar a limitação da memória humana. A fala de Theuth limita-se a descrever ao rei essa operacionalização do sistema de codificação. Interessa-lhe apenas um processo narrativo mínimo que, não por acaso, ocorre com frequência nos comerciais de nossos dias. São frequentemente marcados por um antes e um depois, o segundo melhor do que o primeiro graças à intervenção da tecnologia que, nesse contexto, só pode ser vista como algo que expande e amplia o potencial do estado de coisas anterior. E o contexto dessa narrativa mínima é, exclusivamente, aquele da operacionalização: um antes modificado por operações tecnológicas transforma-se em um depois melhorado.

A resposta do rei complica significativamente essa narrativa, porque a ela acrescenta a dimensão problematizadora de uma economia histórica e cultural que insere a operacionalização em um contexto mais amplo de perdas e ganhos do sujeito e da cultura afetados pela tecnologia:

Caro Theuth, o mais industrioso dos meus súditos, alguns se distinguem em inventar artes (ta technês); outros, em julgar o benefício. Está claro que tu, o pai das letras, por partidarismo, afirmas o contrário do efeito delas. Asseguro-te que elas causarão esquecimento (lethe) às psiques e desinteresse pela memória (mneme). A confiança dos iletrados repousará na escrita (graphé), em caracteres exteriores, estranhos, e não no interior, em reminiscências (anámnesis). Descobriste uma droga não para a memória, mas para a recordação (hupómnesis). Oferecerás a teus discípulos aparência (doxa) de saber, mas não a verdade (alétheia), pois os homens de letras se tornarão eruditos sem instrução; verão a si mesmos como intérpretes de muitas coisas, embora a maioria deles 
não saberá interpretar nada. Serão insuportáveis, sábios na aparência (doxósophos) e não sábios (sophós) de fato (PLAT0, 1925, p. 274-275).

$\mathrm{Na}$ resposta do rei, evidencia-se um entendimento da tecnologia em que o aspecto instrumental serve mais para ocultar do que para revelar a verdadeira natureza da produção tecnológica, que é mais força modeladora do real do que caixa de ferramentas. Nesse contexto, Theuth seria uma espécie de intelectual orgânico, já que só pode falar a partir do contexto produtivo a que está filiado, ou seja, o contexto tecnocrático. 0 texto platônico lembra, com propriedade, que a escrita era apenas a sua invenção (technas) mais recente, antecipada que fora pela matemática, pelo cálculo, pela geometria e pela astronomia (PLATO, 1925, p. 274). Theuth especializa-se em fabricar codificações do real para torná-lo passível de manipulação e controle. Em todos os casos, resulta da codificação um modelo do objeto representado que é, ao mesmo tempo, redutor e produtivo, já que traduz e transforma o concreto em uma forma de conhecimento abstrata e caracterizada por força operacional. É o caso, por exemplo, da operacionalidade que, transformando as formas naturais em círculos, triângulos e retângulos, torna possível as formas de representação que produzem tanto a arte como o artefato. Thamus, o rei, desloca essa perspectiva, que percebe apenas as vantagens da nova tecnologia, para uma inevitável economia cultural de perdas e ganhos. Há um preço a pagar para cada mudança comportamental causada pela tecnologia. A cada uso de uma faculdade humana corresponde um desuso, a cada nova forma de conhecimento, a possibilidade de perda de outro, que se torna obsoleto. Em resumo, o uso de um artefato protético, que substitui ou incrementa uma função humana, traz como efeito colateral uma certa atrofia do organismo. 
Thamus constrói, portanto, uma crítica da perspectiva operacional e tecnocrática por meio de um deslocamento. 0 operacional, entendido em um novo contexto, significa outra coisa. Esse novo contexto é, precisamente, aquele que entende a tecnologia não apenas como um instrumental que desencadeia operações e implementa processos existentes, mas como uma força ambiental que afeta aqueles que a utilizam, alterando suas práticas e comportamentos e tornando-os diversos do que eram. $\mathrm{O}$ uso da escrita como prótese exterior, que complementa e expande o uso limitado da memória interior, resultaria, aos poucos, no uso cada vez menos intenso da memória interior, já que a informação que deveria ser antes retida na memória humana existe agora armazenada e disponível na escrita. A escrita, diz o rei, causará "esquecimento (lethe) às psiques e desinteresse pela memória (mneme)". E poderia, ainda, ser a causa de uma disseminação errônea de sentidos que, circulando no meio escrito e afastando-se de sua origem na voz do autor, escapariam ao controle que tal presença original poderia supostamente exercer.

O julgamento de Thamus, que prioriza a voz e a presença em detrimento da escrita (marcada pela ausência da voz controladora do sentido verdadeiro e, portanto, não confiável), não pode hoje, e particularmente após a crítica ao logocentrismo feita por Jacques Derrida, ser aceita sem questionamentos ${ }^{1}$. A história da escrita e do livro enquanto expansão do conhecimento e preservação da memória cultural mostraria, sem sombra de dúvida, que o julgamento de Thamus é tão ou mais partidário do que a perspectiva operacional e otimista

1 Ver, em particular, o capitulo "Writing before the letter" (DERRIDA, 1976). Derrida afirma que a história da metafísica "atribuiu sempre a origem da verdade em geral ao logos: a história da verdade, da verdade da verdade, trouxe sempre consigo [...] a desvalorização da escrita e a sua repressão no exterior da fala" (1976, p. 3). 
de Theuth. Optar por uma em favor da outra, como faz o rei, é o resultado de um problema de miopia crítica. Mais apropriado e produtivo seria pensar a escrita e a fala não apenas como tecnologias alternativas, mas também como complementares. E trata-se de complementaridade que tem um potencial de crítica, já que o complemento constitui uma segunda dimensão (aquela de uma definição alternativa da tecnologia) a partir da qual é possível repensar a definição anterior e vice-versa. 0 fato de a voz e a comunicação presenciais terem o seu lugar e a sua hora não precisa necessariamente conduzir ao banimento da escrita para fora da história da verdade. Essa perspectiva crítica dupla, que se dirige dialeticamente tanto à proposta do rei como à do inventor, pode, portanto, constituir o lugar crítico a partir do qual se torne possível entender o que se perde e o que se ganha quando do aparecimento de uma nova techné.

É bem possível que o aparecimento de uma nova tecnologia traga sempre consigo uma ênfase imediata na perspectiva operacional. Trata-se de entender, de imediato, como a nova tecnologia funciona mediante seu uso sistemático no maior número possível de práticas. É também possível que essa ênfase operacional venha acompanhada de um otimismo exagerado a respeito do potencial da nova tecnologia. Tentar ir além desse otimismo inicial, como faz Thamus, é tarefa de uma crítica da tecnologia capaz de deixar entrever, para além do operacional e tão rigorosamente quanto possível, uma economia cultural de perdas e ganhos.

\section{0 hipertexto operacional}

O livro de George P. Landow, The Convergence of Contem- 
porary Critical Theory and Tecnhology (1992), foi o primeiro estudo sistemático dos possíveis relacionamentos entre o hipertexto eletrônico e a teoria literária. Encontra-se no texto uma passagem que, não por acaso, guarda certas semelhanças com a fala de Theuth: "Na medida em que qualquer leitor tem o poder de entrar no sistema e nele deixar a sua marca, nem a tirania do centro e nem a da maioria conseguem se impor. Pela sua própria natureza, o texto aberto confere poder ao leitor" (LANDOW, 1992, p. 173).

George P. Landow não é aqui o inventor da nova tecnologia hipertextual, mas, como Theuth, teoriza sobre ela em uma narrativa mínima de um antes e um depois que se referem, neste caso, ao leitor. Mas Landow vai além de Theuth, porque explica o novo leitor, agora mais poderoso, em termos de uma economia social de redistribuição de poder que deve necessariamente ocorrer com o aparecimento de uma nova tecnologia. "A tecnologia", Landow (1992, p. 171) explica, "sempre confere poder a alguém, ou a um grupo social, e há um preço a pagar. A pergunta a ser feita, portanto, diz respeito ao grupo ou aos grupos sociais que se tornam mais poderosos"

Para que o leitor adquira mais poder, é necessário que alguém ou alguma coisa o perca. Os grandes perdedores são, aqui, o livro e o autor tradicionais que, de formas diversas, exerceram durante séculos o poder de controlar significativamente tanto o comportamento do leitor como a produção de significados. 0 autor tradicional constitui um centro de poder que organiza linearmente o seu texto em sentenças, parágrafos, capítulos, começo, meio e fim. Dificilmente consegue o leitor comum escapar de tais constrangimentos. 0 autor de hipertextos, por outro lado, produz o seu texto de acordo com o princípio da quebra da linearidade, porque trabalha com um paradigma de construção textual que subs- 
titui sequências de sentido por saltos entre blocos de significado. Landow entende a passagem do texto ao hipertexto (e de autores e leitores do primeiro para autores e leitores do segundo) em termos de uma mudança radical de paradigma que constitui nada mais nada menos do que "uma revolução no pensamento humano":

Creio que uma mudança de paradigma começou a acontecer nos escritos de Jacques Derrida e Theodor Nelson, Roland Barthes e Andries Van Dam. Aqueles ligados à área de computação conhecem bem as idéias de Nelson e Van Dam; e aqueles que trabalham na área de teoria literária e cultural conhecem igualmente bem as idéias de Derrida e Barthes.

Todos eles, como muitos outros que escrevem sobre teoria literária, argumentam a favor do abandono de sistemas conceituais baseados em idéias de centro, margem, hierarquia e linearidade e da sua substituição por sistemas de multilinearidade, nódulos, links, e redes (LANDOW, 2006, p. 1).

0 termo "paradigma" partilha com outros conceitos explicativos, como "modelo", "gênero" e "estrutura", o problema de tentar explicar classes de objetos por meio de procedimentos que, priorizando a identificação de semelhanças, relega a um segundo plano as diferenças. 0 sucesso desses procedimentos depende sempre da subordinação do fluxo temporal à dimensão do espaço geométrico e abstrato em que, por assim dizer, um presente eterno permite justapor lado a lado objetos dissimilares purificados de suas diferenças. Subordinando o tempo ao espaço e a história à estrutura, o paradigma torna possível a percepção idealizada do mesmo no diverso e da unidade na multiplicidade. É óbvio que não se faz história sem estruturas e que a estrutura não escapa da historicidade. Mas é para o desequilíbrio entre essas duas dimensões que o conceito de paradigma chama a 
atenção, em contraste com o discurso explicativo ideal que tentaria, sempre de forma precária, equilibrar movimento temporal e imobilidade geométrica, atentando sempre para as limitações impostas tanto pelo excesso de fluxo como pela exorbitância da estrutura.

Uma leitura crítica da obra de Landow apontaria para a prioridade dada mais às semelhanças a serem obtidas pelo procedimento paradigmático do que para as diferenças históricas. Manifesta já no título do volume, que propõe uma convergência entre hipertexto e teoria literária, a ênfase nas semelhanças torna-se mais específica e problemática na justaposição de nomes citada acima: de um lado, Derrida e Barthes; de outro, Ted Nelson e Van Dam, todos considerados como adversários "de sistemas conceituais baseados em idéias de centro, margem, hierarquia e linearidade" e partidários de "sistemas de multilinearidade, nódulos, links e redes". Mas será que as constantes paradigmáticas de centralização e descentralização ocorrem da mesma forma ou em contextos idênticos? E será que a identificação das diferenças específicas implícitas nas constantes paradigmáticas não apontaria para o problema maior da justaposição de semelhanças genéricas, ou seja, o problema da generalização conceitual extremada que tornaria de pouca utilidade e, no limite, inútil, o sistema de semelhanças encontrado? Landow não enfrenta sistematicamente o problema. Limita-se a dizer que "o rizoma é, essencialmente, um contra-paradigma, algo que não se realiza em nenhum momento ou cultura específicos, muito embora possa servir como um ideal para o hipertexto" (LAND0W, 1992, p. 62, o itálico é meu).

Em que consistiria, mais precisamente, esse ideal para além de qualquer prática? 0 próprio Landow sugere a possibilidade de um aprofundamento da questão quando afirma 
que o rizoma, como o "hipertexto entendido em sua forma mais genérica", rejeita "qualquer idéia de eixo genético ou estrutura profunda" (LANDOW, 1992, p. 60). O hipertexto genérico é aqui o equivalente do conceito ideal de rizoma. A distinção entre real e ideal, específico e genérico seria uma explicação satisfatória se não fosse possível encontrar estruturas rizomáticas na realidade material e histórica. Ora, essas estruturas existem: a linguagem é um exemplo. Se Deleuze estiver falando de realidades similares, que rejeitam origens e estruturas profundas, então a comparação entre o rizoma como ideal e o hipertexto como real cai por terra.

Pouco convincente em termos de rigor teórico, a escolha que faz Landow para explicar a convergência entre regimes pós-estruturalistas de descentralização e hipertexto em termos de real versus ideal é, contudo, uma indicação valiosa para o entendimento de sua obra como um todo. Trata-se de obra que tende a privilegiar mais uma prática de produção de redes hipertextualizadas de excelente qualidade do que uma postura crítica em relação ao hipertexto. Landow coordena atualmente a apresentação de três websites, dedicados respectivamente a estudos da era vitoriana, ao pós-colonialismo, e a questões relativas à teoria crítica, ciberespaço e hipertexto. São produções de grande valor e reconhecidas internacionalmente. Receberam prêmios que reconhecem sua excelência de instituições australianas, russas, inglesas e norte-americanas, entre outras.

\section{William Blake na rede eletrônica: o poder da tecnologia}

A excepcionalidade da obra do poeta inglês William Blake 
faz dele, muito provavelmente, o autor que melhor exemplifica o que acontece quando um texto literário migra do meio impresso para o meio eletrônico. É que, na produção blakeana, tudo parece indicar que o poeta, trabalhando no meio impresso, teve sua capacidade expressiva limitada pela velha tecnologia de Gutenberg. Blake foi, por assim dizer, um poeta que usou o livro para expressar-se em multimídia, já que não apenas escrevia poemas, mas deles fazia traduções gráficas, que chamava de "iluminuras". No passado, essa produção em multimídia não podia ser editada para comercialização em virtude de sua forma idiossincrática, resultado do hibridismo de poesia e pintura. Hoje, pode ser exemplarmente traduzida (o que significa que essa tecnologia artesanal pode, também, ser exemplarmente distorcida) para uma tecnologia eletrônica, consideravelmente mais poderosa do que a tecnologia empregada no momento de origem da criação poética. Preocupado com a dificuldade que tinham artistas pouco conhecidos para publicar suas obras, a menos que conseguissem eles mesmos reproduzir seus próprios textos, Blake desenvolveu um método sui generis de composição: imaginou um autor capaz de ser, ao mesmo tempo, produtor, editor e distribuidor de seus textos. Exímio praticante tanto da arte literária como da pictográfica, Blake desenvolveu um sofisticado processo caseiro de produção de textos em que poesia e ilustrações tornavam-se inseparáveis e complementares.

A história da editoração da poesia blakeana foi profundamente afetada por esse método idiossincrático de produção literária. Quando a cultura vitoriana, que não tinha ainda a tecnologia fotográfica para reproduzir os volumes originais, redescobriu a importância de Blake, a única alternativa para a divulgação de sua obra era reduzir a produção em multimídia a meros textos impressos, excluindo-se a parte 
pictográfica. 0 problema dessa obra reduzida a meros textos só começa a ser questionado sistematicamente a partir de 1970, quando um grupo de estudiosos (particularmente David Erdman, John E.Grant e W. J. T. Mitchell) apresentou argumentos sólidos para fundamentar uma redefinição da prática de leitura do poeta-ilustrador em termos da inseparabilidade da poesia e das imagens. Essa proposta de releitura, contudo, esbarrava em dificuldades imensas, uma vez que cada versão textual e pictográfica de um poema era diversa das outras. Ler o Livro de Thel em uma versão é uma experiência que difere daquela que aconteceria em outra, o que significa que uma leitura mais exigente do poema tornaria necessário o manuseio de todas as cinco produções originais existentes. Nesse caso, o leitor teria que dispor de recursos para a consulta de livros e arquivos raros e de difícil acesso. No momento atual, e graças à tecnologia digital, esse problema de acesso não mais existe: O Arquivo Blake colocou, na internet e gratuitamente (pelo menos por enquanto), cópias de todas as versões. Qualquer leitor que disponha de um computador e um modem, em qualquer lugar do planeta, pode acessar todas as versões existentes. Parafraseando um pouco o texto platônico no momento atual, seria possível dizer que os leitores de Blake podem tornar-se agora mais sábios e instruídos.

Operacionalizado pela tecnologia digital, o texto blakeano torna-se, ao que tudo indica, melhor e mais acessível. E esse avanço qualitativo e quantitativo torna-se ainda mais significativo quando se considera a excelência da versão eletrônica. Quando os três editores do Arquivo (Morris Eaves, Robert Essick, e Joseph Viscomi), todos especialistas na obra de Blake, começaram a trabalhar no projeto, a proposta era constituir um arquivo eletrônico que serviria de exemplo para futuros projetos de bibliotecas virtuais: 
Nosso projeto [deverá contribuir] para o estabelecimento de um padrão nos estudos especializados de textos e de história da arte em um momento decisivo da sua implantação no meio eletrônico. Para uma vasta comunidade internacional de historiadores da arte e de críticos literários, entre outros interessados, o Arquivo Blake [será] um valioso instrumental de referência, tornando disponíveis reproduções de alta qualidade de um conjunto importante de obras - boa parte das quais não reproduzidas anteriormente, ou reproduzidas precariamente, ou apenas em volumes raros - e permitindo tanto o acesso como o uso de tal conjunto em novas formas capazes de fazer avançar o conhecimento interdisciplinar, em áreas que dele necessitam, tanto qualitativa quanto quantitativamente (EAVES, 2005, p. 6).

A alta qualidade da reprodução hipertextualizada de Blake torna-se visível tanto no cuidado com a preparação dos textos como das ilustrações. No caso dos textos, o leitor pode optar por consultar a edição clássica de David Erdman (Complete Poetry and Prose), hipertextualizada de forma a permitir buscas exaustivas de palavras ou frases. Pode também, para uma leitura mais exigente, consultar cópias de obras em edições diversas, em muitos casos edições de difícil acesso. É no caso das ilustrações, contudo, que se manifesta mais claramente a excelência do trabalho editorial. A reprodução das imagens, de qualidade tão próxima do original quanto possível, é facilitada pelo uso de tecnologia digital de ponta, o que possibilita o estudo rigoroso das ilustrações em um nível "até agora impossível sem o acesso direto aos originais" (EAVES, 2005, p. 5). Os editores garantem "que as imagens do Arquivo são mais fiéis aos originais em escala, cor e detalhe do que as melhores reproduções fotográficas (impressas), com exceção de alguns poucos casos extraordinários" (EAVES, 2005, p. 5). 
Essas imagens de alta resolução podem ser examinadas com mecanismos de procura: o usuário pode localizar, por exemplo, todas as gravuras em que aparecem pássaros e figuras humanas relacionados a poemas específicos. E cada uma das imagens pode ser manipulada de maneiras que seriam impossíveis no meio impresso. Os dois principais programas de software que possibilitam essa manipulação foram desenvolvidos especificamente para o arquivo, com o apoio do Instituto para Tecnologia Avançada nas Humanidades, localizado na Universidade da Virgínia. O primeiro, denominado "Imagesizer", permite ao usuário ajustar o tamanho das imagens a serem examinadas e visualizá-las nas dimensões originais, ampliadas, ou de forma a adaptá-las ao tamanho e ao potencial do monitor do usuário. O segundo, denominado "Inote", permite a visualização de anotações a respeito da imagem e de seus detalhes mais importantes: contexto histórico, forma de produção etc.

Excelente em termos qualitativos, o Arquivo pouco ou nada deixa a desejar em termos de quantidade de informação. Com apoio financeiro e institucional de poderosas instituições, as aquisições do Arquivo cresceram rapidamente. Em texto que descreve em detalhes o "plano do Arquivo", os editores apresentaram um balanço dos resultados obtidos até o ano de 2003: "4200 imagens, incluindo pelo menos uma cópia de cada livro ilustrado e, em muitos casos, cópias múltiplas, bem como um grande número de pinturas, ilustrações, alto-relevos, manuscritos e obras tipográficas do poeta" (EAVES, 2005, p. 17). Não custa lembrar que essa enorme quantidade de informação não poderia, na prática, ser colocada em forma de livro impresso. É que o Arquivo permite que se considere a obra completa de Blake de forma mais vasta do que seria possível no meio impresso. 0 meio digital 
permite pensar essa obra não apenas em termos do conjunto canônico de livros ilustrados, mas do conjunto completo de uma obra não-canônica: ilustrações e pinturas feitas pelo poeta para acompanhar a obra de outros autores e textos, como ilustrações para livros da Bíblia, da Divina Comédia de Dante, do Paraíso Perdido, de Milton, de Edward Young, e de Thomas Gray. Vale lembrar que a inclusão de tais textos não deve, necessariamente, ser entendida como menos significativa do que a inclusão dos textos canônicos. Como lembram os editores, essa obra pictográfica suplementar "revela relações formais próximas com as ilustrações dos livros ilustrados, e é duplamente importante: apresenta exemplos típicos da obra blakeana em seu todo e constitui, hoje, material a ser cuidadosamente examinado por especialistas na obra de Blake" (EAVES, 2005, 16).

Dada a capacidade de armazenamento do meio digital, essa lógica de inclusão progressiva de textos pode estender-se indefinidamente no tempo, o que resultará no acervo eletrônico que os editores chamam de "Blake ampliado" (augmented Blake), ou seja, uma obra em processo permanente de construção e sempre incompleta. Nela a inclusão inicial dos textos mais conhecidos do poeta (como Songs of Innocence and of Experience e The Marriage of Heaven and Hell) é apenas um começo. A esse acervo inicial serão progressivamente acrescentadas as obras do Blake pintor e ilustrador: um conjunto de pictografias produzidas separadamente dos poemas, hoje visto como parte importante da história da pintura do século XVIII. É o caso das ilustrações da Bíblia e da obra de John Milton. Nesse arquivo expandido, novas contextualizações da obra do poeta poderão ser estudadas pelos especialistas. Certas ilustrações comerciais produzidas por Blake, por exemplo, "podem chamar a atenção para uma convergência 
importante entre o texto ilustrado de Visions of the Daughters of Albion (1793) e as ilustrações preparadas para o livro de J. G. Stedman, Narrative of a Five Years' Expedition, against the Revolted Negroes of Surinam" (EAVES, 2005, p. 2). E esse arquivo ampliado torna-se acessível, pela primeira vez, a todos os leitores com acesso à rede, e não apenas a alguns estudiosos privilegiados. Como explicam os editores,

não existia, até o momento, uma base de conhecimentos e tecnologias suficientes para imaginar, e muito menos para realizar, uma edição tanto quanto possível completa de um autor multimídia [como é o caso de Blake]. A tradição hegemônica na editoração de Blake enfatizou quase exclusivamente o texto literário. 0 Blake histórico, um profissional nas artes da pintura e da ilustração, que considerava a poesia como apenas mais uma de suas práticas criativas, transforma-se agora em um poeta reconhecido também por suas atividades nas artes visuais, que eram anteriormente relegadas a um segundo plano, como uma produção marginal e quase invisível. [A publicação puramente textual da obra] era o resultado do que um dos primeiros críticos de Blake, o poeta Swinburne, chamou de "necessidade implacável” - os impedimentos econômicos e tecnológicos que impediam a reprodução de imagens precisas em edições impressas [...]. Em conseqüência, muitos estudiosos conhecem a produção pictográfica, ou a textual, mas não ambas. Em sua metodologia, o Arquivo Blake é uma tentativa de recuperar esse equilíbrio histórico com a utilização da síntese tornada possível pelo meio eletrônico. Acreditamos que o resultado, nos moldes de um protótipo de um arquivo editorial, poderá contribuir para alterar os paradigmas de acesso à arte e à literatura da época de Blake e, ao mesmo tempo, propiciar uma mudança nas formas de abordagens do poeta (EAVES, 2005, p. 1). 
Otimizado em termos de qualidade hipertextual e de seleção do material, o arquivo prima também pelo esforço para atender às necessidades de um público leitor tão amplo quanto possível. Nesse contexto, o problema maior é disponibilizar, aos usuários que dispõem apenas de equipamentos eletrônicos menos sofisticados, imagens tão próximas quanto possível dos originais. A solução foi tornar o arquivo flexível, dando opções diversas de acesso ao material. Aos usuários que dispõem de máquinas de maior velocidade, o arquivo recomenda a utilização de certos links; aos que usam máquinas lentas, oferece links alternativos, adequados ao poder inferior de memória. Dada essa flexibilidade, o arquivo pode ser utilizado por grupos diversos de leitores: especialistas que dispõem de recursos sofisticados para recepção de imagens, estudantes utilizando máquinas menos sofisticadas e leitores comuns interessados apenas em textos.

\section{William Blake nas malhas da rede}

Se o texto de Blake foi produzido para uma leitura em diálogo com a ilustração, e se essa possibilidade de leitura visualmente contextualizada foi historicamente reprimida pelo meio impresso, parece forçoso concluir que a tecnologia digital torna possível, hoje, um exercício de leitura que é mais fiel ao texto original do poeta do que as leituras que, no meio impresso, restringem o sentido do poema apenas ao texto. Muito embora haja algo de verdade em tal conclusão, seria precipitado aceitá-la sem questionamentos. Hillis Miller vem chamando a atenção da crítica, insistentemente, para a necessidade e a urgência de uma reflexão mais cuidadosa e profun- 
da sobre a produção de literatura em hipertexto.

Em ensaio disponível no próprio acervo dos Arquivos Blake, sob o título de "Blake Digital", Miller (2005) reconhece as vantagens principais inerentes às novas tecnologias: a recuperação da dimensão de multimídia em Blake e outros autores da Era Vitoriana que produziram textos ilustrados; e a motivação crítica para uma nova leitura de Blake, capaz de valorizar o visual que tinha sido reprimido em edições impressas anteriores, inclusive as melhores, como a de David Erdman. 0 preço a pagar por tais vantagens são, contudo, as profundas alterações que resultam da migração da obra de um meio para o outro, particularmente quando se considera a importância das condições de produção original. 0 contexto de produção das gravuras e textos em alto relevo poderia ser descrito em termos de uma indústria caseira, operada por Blake enquanto autor, gravador em alto relevo, pintor e escritor. E a produção resultante de tal indústria era claramente marcada pelo que Walter Benjamim chamou de "aura", ou seja, cada objeto estético produzido tornava-se único e diverso de todos os outros, inclusive de outras cópias reproduzidas a partir da matriz original (as cores das cópias de um mesmo poema, por exemplo, variam de versão para versão, como mencionei anteriormente). A utilização do meio digital altera radicalmente essas condições materiais de produção. 0 que era uma indústria caseira de alcance diminuto transforma-se em um empreendimento de alto custo e de vasto alcance. Cada imagem, cuidadosamente preparada e traduzida na linguagem digital de zeros e uns, viaja em alta velocidade pelo planeta e pode ser recuperada, com fidelidade quase perfeita, em qualquer canto do mundo em que haja um computador equipado com um modem. Um Blake local e único transforma-se em um Blake global a ser infinitamente copiado e re- 
produzido, e isto em um meio eletrônico que sofre múltiplas mediações cada vez que uma cópia é traduzida na linguagem digital e eletronicamente armazenada em um servidor para redistribuição imediata.

Para Miller, esse contexto de produção material, em que um Blake com os dedos sujos de tinta marcava o papel a ser manuseado pelo leitor, é parte integrante da produção poética. Uma vez traduzida para o meio digital, essa materialidade perde-se nas imagens fantasmagóricas que aparecem na tela do computador. Enquanto o texto impresso pode reter, em parte, a lembrança e os vestígios dessa materialidade, o mesmo não ocorre no processo de transcodificação digital, que tem como resultado o aparecimento da imagem a ser manipulada pelo leitor. Um Blake que tinha uma historicidade material transforma-se em um Blake fantasmático. Miller sugere que o próprio Blake, se consultado, poderia talvez considerar a reprodução digital de sua obra como uma "perversão horrível" do texto que produzira como artista e artesão (MILLER, 2005, p. 1). É que o próprio autor definia a sua obra poética, no seu tempo histórico de produção, como textualidade fabricada por um poeta-profeta e marcada pelo poder performativo de operar mudanças em seus leitores. Estes teriam a sua maneira de perceber o mundo transformado por meio da depuração dos portais da percepção, ou seja, da depuração dos seus sentidos desgastados pela crença na separação entre corpo e espírito. Note-se que o texto fantasmático apresentado na tela do computador produz, necessariamente, essa separação: a materialidade do livro tem um corpo, assombrado pelo espírito do Blake criador, enquanto o texto fantasmático na tela do computador está liberto do material e do corpóreo. Nesse contexto histórico, já não faz sentido falar de uma obra isolada, mas de um po- 
eta-profeta, utilizando o meio impresso e pictográfico (ou seja, a tecnologia existente na época) para afetar (com uma textualidade performativa) o seu leitor de uma forma específica e determinada pelo tempo histórico.

Miller lembra que o próprio Blake chamou a si a tarefa de definir o seu método de produção poética em termos da metáfora da abertura das portas da percepção. Seu objetivo era abrir tais portas de forma a produzir no leitor o entendimento da unidade do corpo e do espírito, do material e do imaterial. Em $O$ casamento do céu e do inferno, o poeta define explicitamente a conexão entre a forma material de produção da poesia e o seu objetivo último;

Em primeiro lugar, porém, a idéia de que o homem possui um corpo separado do espírito deve ser eliminada; é precisamente o que farei, praticando a impressão [de poemas] pelo método infernal e usando corrosivos, que no Inferno são considerados saudáveis e medicinais, já que consomem as superfícies das aparências e revelam o infinito oculto ( MILLER, 2005, p. 7).

Como sugere a crítica de Miller, alterado o momento histórico em que a tecnologia permitia utilizar o meio impresso como "método infernal" e corrosivo, os efeitos no leitor não seriam os mesmos e as portas da percepção do leitor pós-moderno que acessa um Blake digital não poderiam ser depuradas da mesma forma. Se o meio desmaterializado pela tecnologia digital depura alguma coisa, não o faz da mesma forma que o meio impresso, contaminado por metal e tinta.

Ampliando um pouco a crítica de Miller, não seria exagerado dizer que o meio desmaterializado acaba por operionalizar o procedimento clássico da ideologia: enfatizar a todo custo o produto em seu isolamento para ocultar o processo 
histórico de produção. Um produto qualquer bem embalado e isolado em uma estante de supermercado convida o consumidor a comprá-lo, sem que nenhuma atenção seja dada ao processo de produção: o plantio, a colheita, o trabalho humano, o intermediário etc. A atenção dada a esse processo de produção, evidentemente, poderia alterar o comportamento do consumidor e complicar significativamente o procedimento de compra e venda. Nesse contexto, a obra fantasmática de Blake disponibilizada na rede eletrônica tende a apagar os traços de sua produção e apresenta-se ao leitor na forma de um produto isolado, auto-suficiente e bem acabado a ser apreciado e consumido em uma tela iluminada.

Apesar de reconhecer que a tradução para o meio digital altera significativamente a poesia de Blake, Miller vê de forma ambivalente o esforço para a hipertextualização da obra completa do poeta. De um lado, perde-se no Blake digital o poeta original, agora liberado do peso da materialidade de papéis, tintas e cores. No momento da produção artística, estas constituíam não apenas um meio, mas também uma mensagem. Ganha-se, por outro lado, um novo Blake, em muitos aspectos robustecido pelo novo meio digital. Não se trata apenas do poder de disseminação maior do meio eletrônico, que facilita o acesso ao poeta para um número muito maior de leitores. 0 novo meio traz consigo, também, uma nova ideologia de comunicação. Entendida criticamente, essa nova forma de produção de textos pode até mesmo auxiliar, por contraste, a compreensão do meio impresso anterior e de suas limitações, particularmente daquelas resultantes dos constrangimentos materiais de espaço e de tempo. E pode, finalmente, operar como mais uma indicação da força de um artefato poético que consegue sobreviver aos diversos meios de comunicação que lhe servem de suporte. 


\section{REFERÊNCIAS}

DERRIDA, J. Of Grammatology. Baltimore, Mariland: The Johns Hopkins University Press, 1976.

EAVES, M. Behind the Scenes at the William Blake Archive: Collaboration Takes MoreThanE-mail.TheJournalofElectronic Publishing,v.3.n.2, dez., 1997. Disponívelem:<http://quod.lib. umich.edu/j/jep/3336451.0003.202?view=text;rgn=main $>$. Acesso em: 15 dez. 2015.

EAVES, M. et al. Plan of the Archive. The William Blake Archive. Ed. Morris Eaves, Robert N. Essick, and Joseph Viscomi, 2005. Disponível em: <http://blakearchive.org/>. Acesso em: 15 dez. 2015.

LANDOW, G. P. (Org.) The Convergence of Contemporary Critical Theory and Technology. Baltimore, London: The Johns Hopkins U. Press, 1992.

LANDOW, G. P. Hypertext 3.0. Baltimore: The Johns Hopkins U. Press, 2006

MILLER, H. J. Digital Blake. The William Blake Archive. Ed. Morris Eaves, Robert N. Essick, and Joseph Viscomi, 2005. Disponível em: <http://blakearchive.org/>. Acesso em: 15 dez. 2015.

PLATO’S. P. In: Plato. Trad. Harold N. Fowler. Cambridge, MA, Harvard University Press; London, William Heinemann Ltd. 1925. 
A LITERATURA NA REDE: UMA LITERATURA ENREDADA?

Artigo recebido em setembro de 2015 e aprovado em dezembro de 2015.

Disponível em: http://seer.fclar.unesp.br/casa 